\title{
CHICKEN'S FRIENDLIER BREEDING HAS A HIGHER ECONOMIC EFFECT
}

\author{
Miro Simonič $\check{c}^{1}$ \\ Anton Vorina ${ }^{2}$
}

DOI: https://doi.org/10.31410/ERAZ.S.P.2019.9

\begin{abstract}
Due to the growing market competition to reduce the cost of breeding chicken's broiler, breeders' brokers are breeding them under worse conditions. An analysis of survey confirms economically-ethically important facts that consumers of chicken's meat are aware that chickens in the farms must have more light and more movement space. Chicken meat consumers are willing to pay a higher price for meat reared and labeled as „DÉDI -chicken-friendlier breeding” and to provide producers with greater profits.
\end{abstract}

Keywords: Chicken's-friendlier breeding, animal welfare, ethics for farmed animals, anthropocentrism, ecocentrism.

\section{CHICKEN'S BREEDING FOR FOOD}

$\mathrm{T}^{\mathrm{h}}$ he more intensive breeding of broiler chicks began in Europe after the First World War, when chickens and hens had grown on larger farms. In the same time, hens were free to walk outside, and were originally cultivated because of the eggs that had a high value on the market. Among the two wars, however, the need for proteins increased due to the growth of the population, and the need for meat was also rising [1]. Farmer's began to deal with the rearing of chickens, so they started building dedicated buildings. The chickens had food and water in the farms, because they were no longer able to find them. Chickens have become entirely dependent on farmers. Since the farmers have begun to build a larger number of farms, they have concluded contracts with slaughterhouses, which are the barrels of chickens at the agreed price of a kilogram of live weight. As far as possible, slaughterhouses have paid farmers to lower prices, and they have kept increasing the number of chickens in existing farms. After 1980, tens of thousands of chickens were cultivated in the farms. When the farm premises became too small, some of the farm's built up floors.

The farms initially had no ventilation devices, and they had no basic sanitary conditions in the absence of heating facilities and animals. The chickens were not vaccinated against diseases which quickly spread rapidly because of the large number of animals, and the animal's mortality increased. After 1953, the United Kingdom started to use poultry feed which allowed healthier and faster chickens to grow [2]. More rapid growth was also provided by new breeds of chickens (Hubbard, Coob, Ross), which allowed the farmers to give a short period of chicken farming.

The end of the seventies and the beginning of the eighties has reached a climax. However, consumers have started to pay more attention to the farming method, and the growing intensity of the farming industry has gradually decreased. In 1999 the EU issued a directive on minimum standards for the protection of animals, so the farmers were forced to increase the chicken's living space and provide them with minimal living conditions [3]. Higher awareness of consumers has also

Faculty of Commercial and Business Sciences, FKPV, Lava 7, 3000 Celje, Slovenia

2 Economics School Celje, Vocational College, EŠ VSŠ, Maroborska 2, 3000 Celje, Slovenia 
been made available to traders to buy chicken meat from producers who could be able to provide more animal-friendly breeding. The meat thus harvested must be marked in such a way that the purchaser detects that the chickens have been bred in accordance with animal-friendly standards.

\section{ANIMAL'S-FRIENDLIER BREEDING}

The first official document on the friendly treatment of animals was made in the 17-century Ireland (Act against Plowing by the Tayle and Pulling the Wooll off Living Sheep) and treats more friendly handling of sheep in their clipping [5]. In the United States of America, the Animal Protection Act of 1966 was signed by President L. B. Jonson [6]. This Act regulates and prescribes more friendly treatment with animals.

In Europe, the World's Poultry Science Association (WPSA) was engaged in the compilation of poultry, founded in London 1912. Through the time periods of the previous century, the rearing was different. Since the First World War, the year 1950 was called „Traditional breeding”, until the year 1990 „Convention for Breeding” (effective breeding) and in the last twenty years „Modern breeding" (with an average animal protection) [4].

In the farms, animals are bred because of their earnings, breeder's use many nutritional supplements to achieve their weight for sale as soon as possible. Additives may contain hormones and antibiotics, which are reflected in meat and meat products sold on the shelves of dealers. The breeding of animals must therefore meet certain standards which prevent the addition of harmful additives and lay down the minimum criteria to be met by farm-rearing facilities and animals in the farms. In recent years, more and more breeders have decided on organic farming, where livestock keepers use natural food and where the rearing must be as natural as possible.
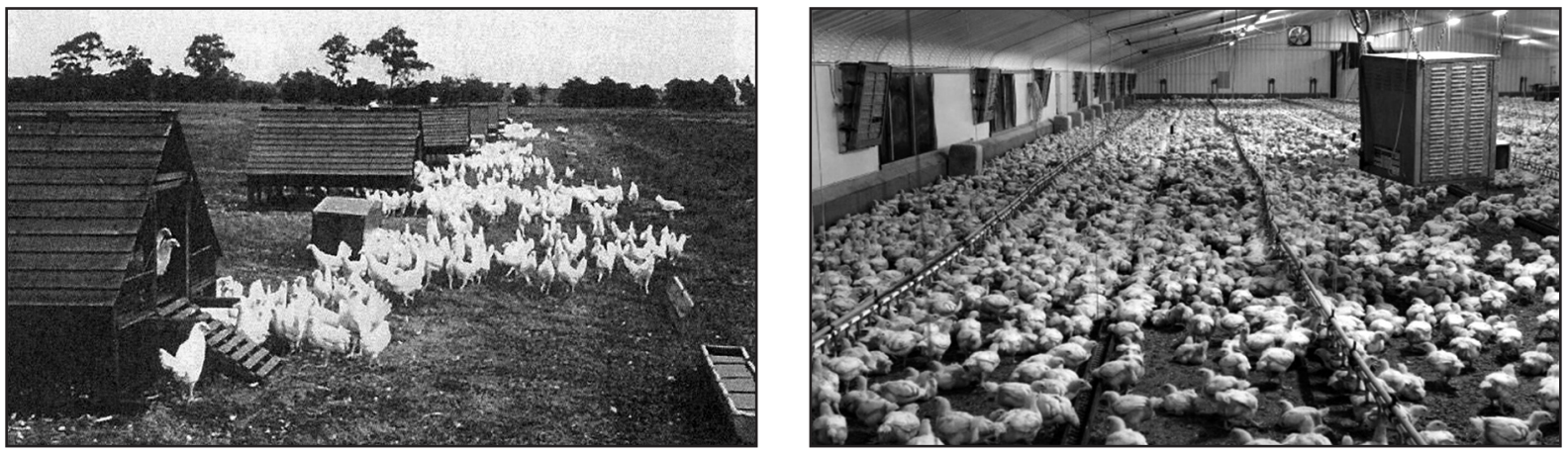

Figure 1: Farming in the years 1933 and 2017 in England (Suffolk) [4].

\section{PROBLEMS RELATING TO THE INADEQUATE BREEDING OF CHICKENS}

Intensive breeding, new breeds of chickens and fodder with growth-enhancing additives have allowed the period of time between 1950 and 1980 to reduce from 12 to 6 weeks. Such breeding continues to represent $70 \%$ of total farming in the United States, UK and Europe. Chicks spend a lot of their short lives in lying, and too fast growth also exerting their hearts and lungs. The lack of space for movement becomes lame and difficult to achieve food and water. Due to the excessive saturation of excrements and moisture, the microbial activity is also increased, causing the contact dermatitis of chickens [7]. 

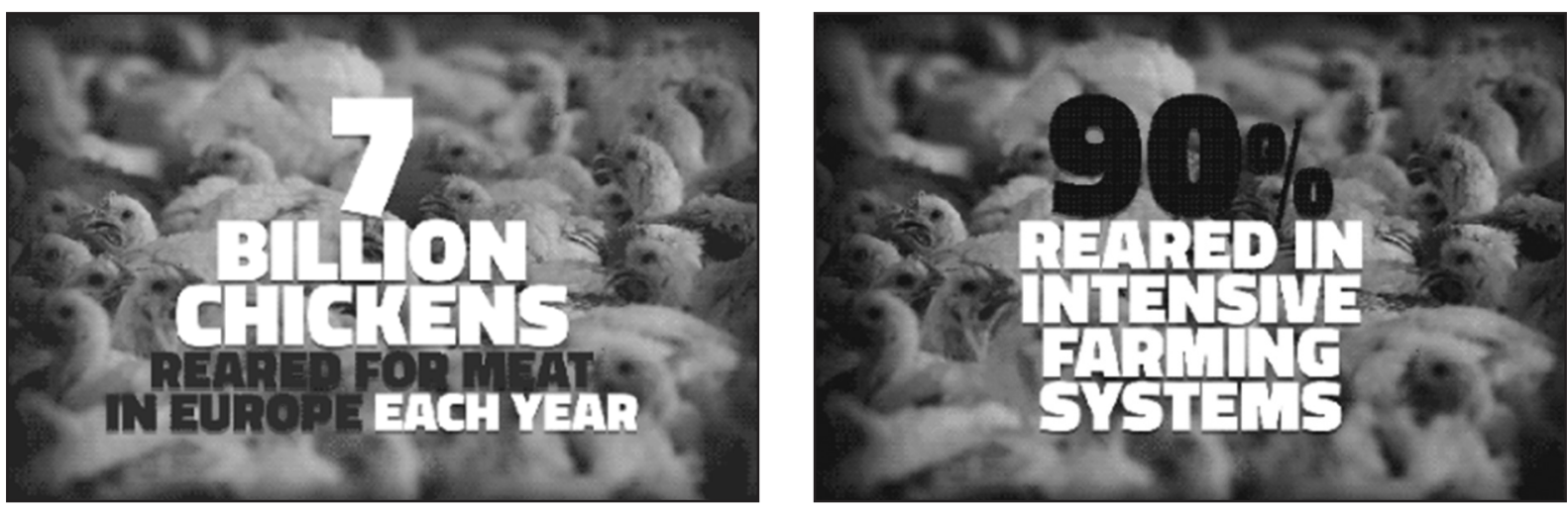

Figure 2: Factory-farmed chickens are packed into overcrowded sheds - often with no natural light and only litter on the floor [8].

Due to the overstocking of animals, many diseases have been encountered during the conventional breeding period, which quickly spread to the entire flock in the farm. In the prevention of the disease, breeders have started preventively vaccinating several days of old chicks and use preventive medicines in fodder. In view of the unconsciousness of the consequences, the animals received excessive amounts of antibiotics. The rearing of the last few decades concerns that medicines work is increasingly rational. More recent methods of rearing chicks are committed to innovative approaches to animal cultivation without antibiotics. With additional training of farmers, better conditions in the farms, more air circulation, more quality feed, water and bedding, there is less chance of animal-burning [9].

The latest research carried out by Heike C. and Nguyen-Phuc H. [10] shows positive results of treatment with the method of appropriate temporal illumination in the farms. They compared the health status of chickens that had little illumination with chickens that lived in high-illumination rooms. The results of the survey showed that chickens in high-illumination farms were much healthier. They even proved that the affected chickens were healed in sufficiently bright areas without antibiotic treatment. This method will allow chickens in the future to be treated without the use of antibiotics in the case of intestinal conditions, which means very profound progress.
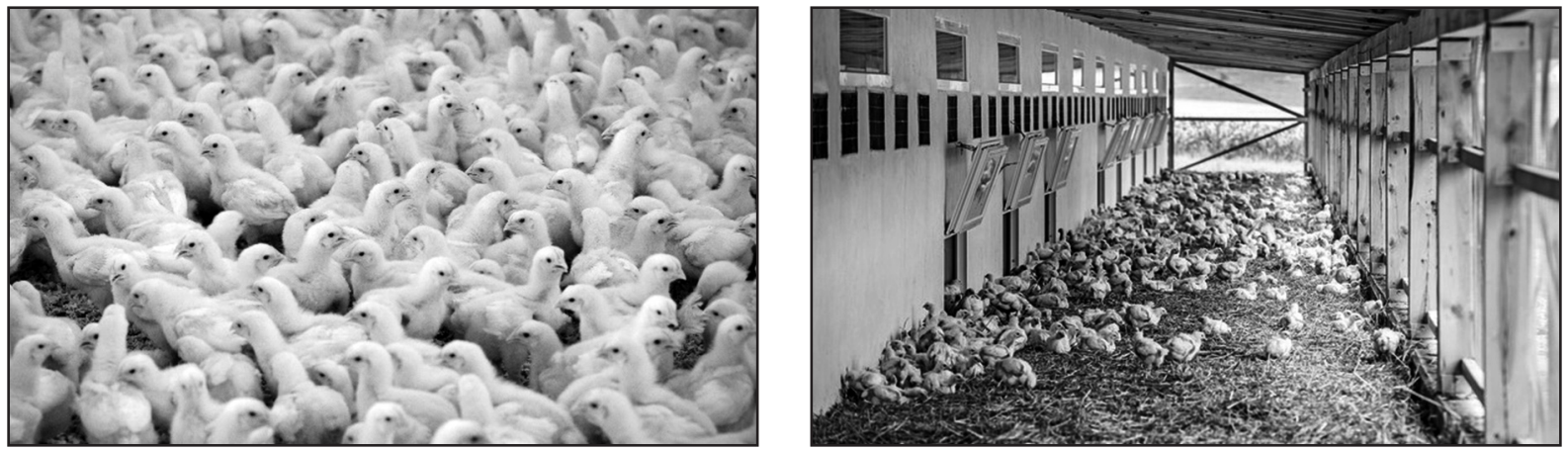

Figure 3: Chicken breeding in USA 2014 [11] and Chicken friendlier breeding in Slovenia (Outspace, Perutnina farm 2014) [12].

The protection of the environment is also increasing with more animal-friendly breeding. The lower concentration of animals in the farms is caused by fewer droppings, and these are also smaller environmental pollutants due to quality food. The smaller number of animals in the farms also consumes less water. 


\section{ETHICAL ATTITUDE TOWARDS THE BREDDING OF CHICKENS}

With a desire for increasing profits, the farmers in the past have focused into increasingly intensive rearing of chickens. Economic profitability has promoted more productive breeding, which is contrary to animal-friendly breeding.

Already in ancient Greece, philosophers have addressed the relationship to animals. Some have advocated that all animals need to be treated as being related, as they are also related to the souls of humans and animals (animalism, Reincarnation, Vitalism). Others [13] have addressed animals from the point of view that they are created only for human benefits (anthropocentrism). In a later period, animal rearing is treated as if animals and humans are part of nature (ecocentrism).

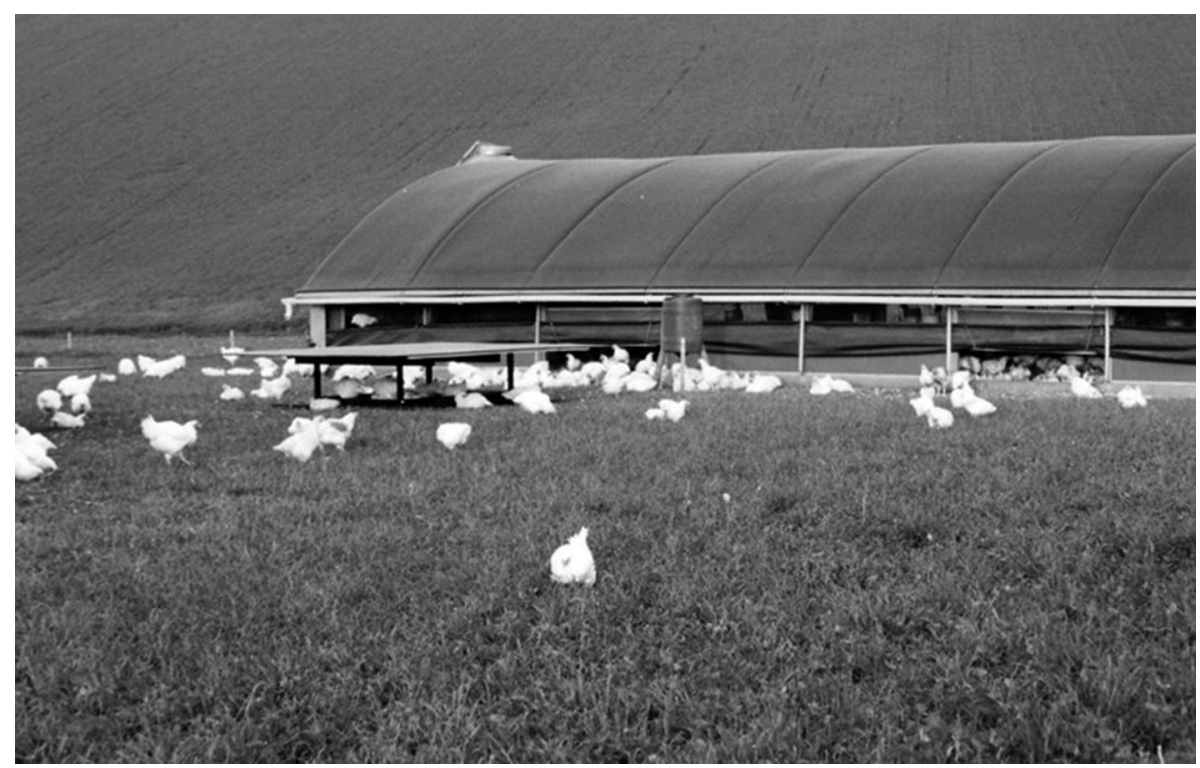

Figure 4: Organic farm in UK [14]

\section{ECONOMIC EFFECTS OF MORE ANIMAL-FRIENDLIER BREEDING}

We can study the breeding of chickens from two aspects. The first aspect is farmers who raise chickens. Their goal is to maximize profits, which they must produce and sell as many more weight chickens in the shortest time as possible with minimum cost. Due to inadequate and increasingly more intensive farming, chickens in too large density suffer increasingly and begin to be affected, and consequently their mortality increases. From an economic point of view, the breeding of chickens for farmer is a loss of profit because it had to buy the chicken, but for him he consumed some food, vaccines, energy for ventilation and other costs associated with breeding.

The second aspect consists of buyers and consumers of chicken meat. Increasing awareness encourages customers to look for meat with markings that ensure that chickens have been bred in animal-friendly farming. Customers are aware that meat from animal-friendly farming has higher quality, since the animals have not been reimbursed unnecessarily during the breeding period and have been healthier because of the larger mobility space. For meat labeled with animal-friendly breeding they are prepared to deduct a higher price. 


\section{RESEARCH}

The aim of the research is to determine how many customers of chicken meat are familiar with the indications that the chickens from which the meat is bred in an animal-friendly way. The Slovenian producer of chicken meat [12], which breeds chickens in the way of animal-friendly farming, denotes products from such farming with the mark DÉDI for Hungary market and PPR for Slovenia market. Furthermore, we were wondering whether buyers are aware that such breeding of chickens is associated with higher costs and that they are prepared to pay a higher price for such reared and labeled meat.

\section{METHODOLOGY}

In order to obtain data, we selected the quantitative method of interviewing respondents with a five-level Likert scale. Respondents were able to choose between following statements: 1 strongly disagree; 5 -strongly agree.

We sent the survey to respondents in Hungary. The questions we have created on the web portal " $1 \mathrm{ka}$ " and were translated into Hungarian language. By analyzing the obtained data, we were looking for answers of questions about how many buyers of chicken are familiar with standard breeding and how many with friendlier chicken breeding (question Q1d). Furthermore, we were interested in whether customers are aware that the chicken-friendlier breeding associated with higher costs and whether they are willing to pay a higher price for products with designation of animal-friendlier breeding of chickens (question Q1e).

Respondents were asked 11 questions about the breeding of chickens and four demographic questions. A set of first six questions concerned the knowledge of standard breeding, and the second set of five questions on chicken-friendlier breeding. By responding to demographic questions, we wanted to find out the gender, age group, net monthly income and education of respondents.

\section{RESULTS AND DISCUSSION}

In the first part of the study, we compared the answers of the respondents to the established label about knowing or not knowing the label, which indicates an animal-friendlier breeding (DÉDI-chicken-friendlier breeding). We compared the answers we received with demographic data of respondents.

Statement Q1d: I know the label „DÉDI-chicken-friendlier breeding” on chicken meat and products.

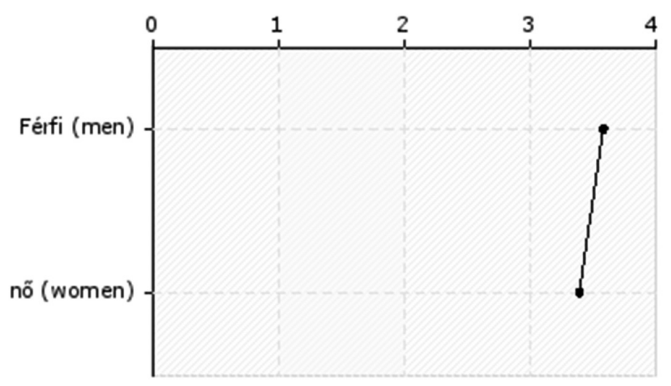

Graph 1: Gender vs Q1d question (I know the label „DÉDI-chicken-friendlier breeding” on chicken meat and products). 
Comment: We received $47 \%$ of answers from females and 53\% from males. The answers show that both sexes of respondents are familiar with labels that characterize animal-friendlier breeding, but this knowledge is very weak. The average response value was between 3 and 4 .

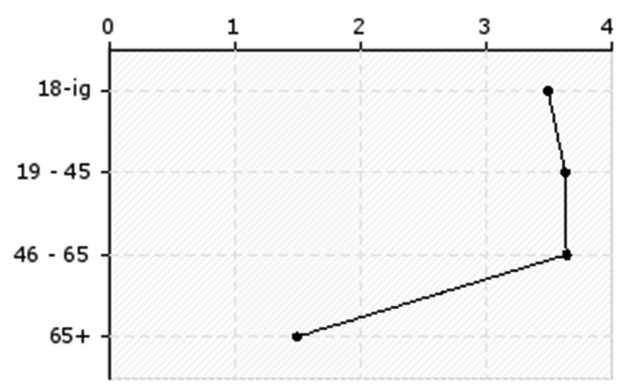

Graph 2: Age group vs Q1d question (I know the label „DÉDI-chicken-friendlier breeding” on chicken meat and products.)

Comment: From Graph 2 it can be seen that the label that characterizes the animal-friendlier breeding is mainly known by middle-aged respondents, while the younger ones are slightly lesser and older than 65 years of age know the DÉDI marking poorly (disagree).

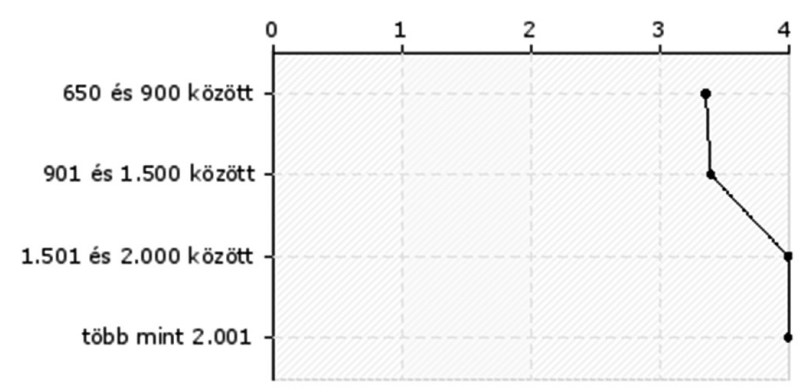

Graph 3: Monthly net incomes vs Q1d question (I know the label „DÉDI-chicken-friendlier breeding" on chicken meat and products.)

Comment: Graph 3 shows that respondents with higher incomes are better acquainted with the DÉDI designation, which indicates a more chicken-friendlier breeding.

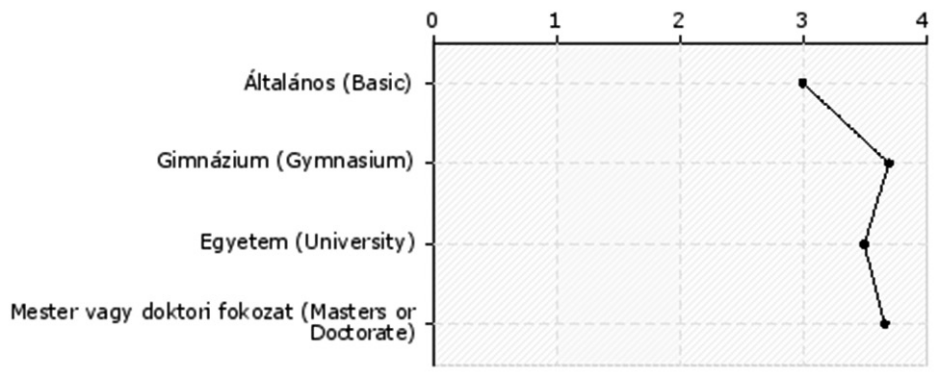

Graph 4: Education vs Q1d question (I know the label „DÉDI-chicken-friendlier breeding” on chicken meat and products.)

Comment: From Graph 4 it can be seen that respondents with a higher education have a slightly better knowledge of the DÉDI label for more chicken-friendlier breeding.

In the second part of the study, we compared the respondents' answers to the pledge on the willingness to pay a higher amount for meat from chicken-friendlier breeding, knowing that such breeding is associated with higher costs. We compared the response we received with demographic data of respondents. 


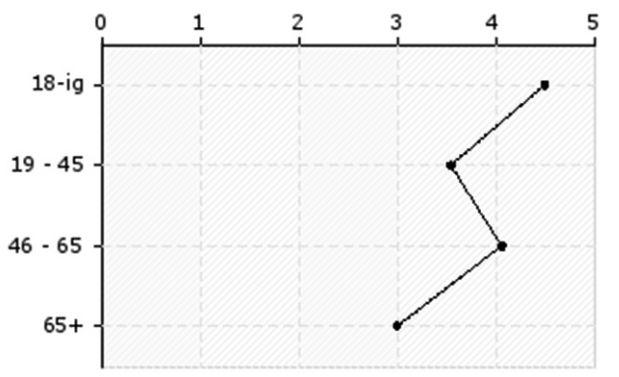

Graph 5: Age group vs Q1e question (For meat of chickens reared in „DÉDI-chicken-friendlier breeding", I am prepared to pay a higher price, since their production is more expensive.

Comment: Graph 5 shows that younger respondents are willing to pay a higher price for chickens labeled DÉDI chicken-friendlier breeding because they are aware that such breeding is associated with higher costs than standard breeding.

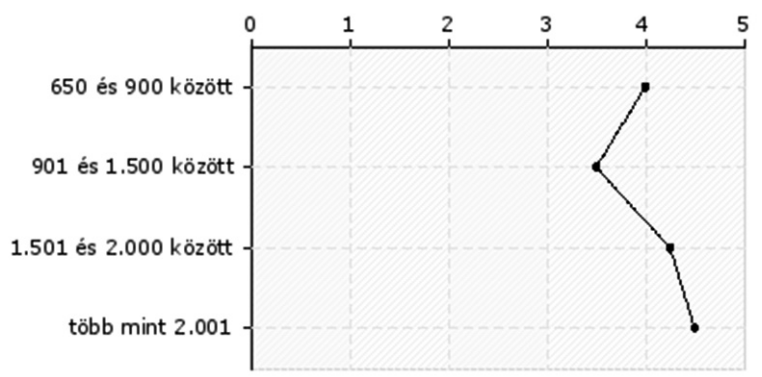

Graph 6: Monthly net incomes vs Q1e question (For meat of chickens reared in „DÉDIchicken-friendlier breeding", I am prepared to pay a higher price, since their production is more expensive).

Comment: Graph 6 shows that respondents with higher net income are willing to pay a higher price for chickens labeled DÉDI chicken-friendlier breeding because they are aware that such breeding is associated with higher costs than standard breeding.

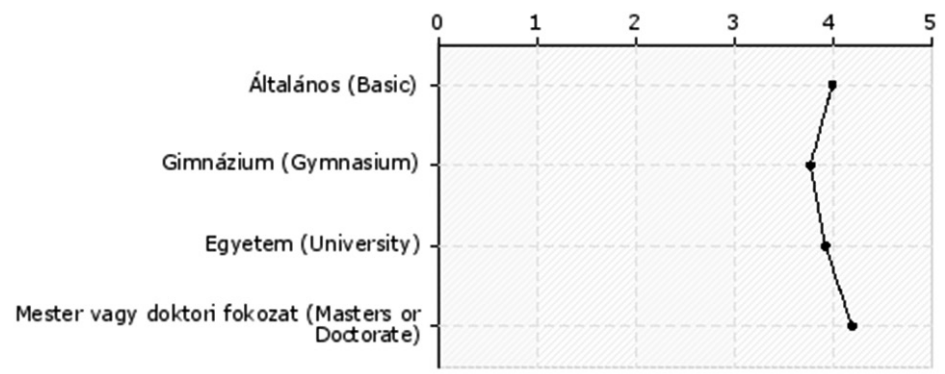

Graph 7: Education vs Q1e question (For meat of chickens reared in „DÉDI-chicken-friendlier breeding", I am prepared to pay a higher price, since their production is more expensive.)

Comment: Graph 7 shows that respondents with a higher education are prepared to pay a higher price for chickens labeled as "DÉDI chicken-friendlier breeding" because they are aware that such breeding is associated with higher costs than standard breeding. 


\section{ANALYSIS}

From the answers received we can conclude that respondents of both sexes are already familiar with the DÉDI designation, which indicates that chicken meat was reared in chicken-friendlier breeding. This designation was known to younger respondents, those with higher income and higher education. On the basis of the above results, the company must direct its marketing activities to the specified target group of customers in order to achieve effective results.

From the answers to the question of how many respondents are willing to pay a higher price because of the awareness that costs for chicken-friendly farming are higher, we can see that the price can increase from 60 to 80 percent in relation to the price of meat from standard breeding.

\section{CONCLUSION}

A higher price can be achieved in real terms only with effective marketing advertising. Producers and traders must communicate sufficiently to buyers about a more prosperous breeding and the benefits that such a breeding provides.

Producers face great competition in the low price of chicken meat products from standard breeding. Consumer awareness that animals deserve better breeding conditions than mass standard breeding is increasingly present in all EU countries and beyond. The thinking of anthropocentrism in many countries already passes into ecocentrism, so it is definitely necessary to direct the chickens into a way of animal-friendlier farming. Products produced in this way will find more and more informed buyers on the market. Modern food companies, however, must always follow the trends that are dictated by informed buyers.

\section{REFERENCES}

[1] Beirne, P. (2009). Confronting animal abuse: criminology, and human-animal relationships. Rowman \& Littlefield Publishers, Inc.

[2] Bessei, W. (brez datuma). Wellfare of broilers: a review. World's Poultry Science Journal, Vol. 62, September 2006. doi:DOI: 10.1079/WPS2005108

[3] Better Chicken. (2019). Available on: Buy Happy: https://betterchicken.org.uk/

[4] Comparison in world farming. About Chickens farmed for meat. Pridobljeno 2019 iz https://www.ciwf.org.uk/farm-animals/chickens/meat-chickens/

[5] Elson, A. Half a century of egg production - 1962 to 2012. Poultry international, str. 41(5): 8-16.

[6] Elson, H. A. (2010). Poultry housing and husbandry. Available on: http://www.lohmann-information.de/content/1_i_46_artikel11.pdf.

[7] Elson, H. A. (2011). Housing and Husbandry of Laying Hens: past, present and future. ADAS Gleadthorpe. Vol. 46 (2), Oct. 2011, Page 16. Meden Vale, Mansfield. UK: Lohmann Information.

[8] Elson, H. A., \& Croxall, R. (2006). European study on the comparative welfare of laying hens in cage and non-cage systems. Available on: European-poultry-science: https://www. european-poultry-science.com/artikel.dll/m06-32mk_MTczNzMy.PDF

[9] Elson, H. A., \& Croxall, R. European study on the comparative welfare of laying hens in cage and non-cage systems. Available on: European-poultry-science: https://www.european-poultry-science.com/artikel.dll/m06-32mk_MTczNzMy.PDF 
[10] EUR-Lex. (1999). Council Directive 1999/74/EC of 19 July 1999 laying down minimum standards for the protection of laying hens. Available on: https://eur-lex.europa.eu/legal-content/EN/TXT/?uri=celex\%3A31999L0074

[11] Fearing, J., \& Matheny, G. (2007). The role of economics in achieving welfare gains for animals. In D.J. Salem \& A.N. Rowan (Eds). The state of the animals 2007 (pp. 159-173). Washington DC: Humane Society Press.

[12] National Chicken Council. (2019). What Consumers Need to Know. Available on: https:// www.nationalchickencouncil.org/about-the-industry/chickopedia/

[13] National Chicken Council. What Consumers Need to Know. Pridobljeno 2019 iz https:// www.nationalchickencouncil.org/about-the-industry/chickopedia/

[14] Parliament of the United Kingdom. (2006). Animal Welfare Act.

[15] Perutnina Ptuj d.d. (2019). Premium poultry breeding. Ptuj. Available on: https://www. perutnina.si/en/products/natur-premium/

[16] Phillips, C. J. (2016). Nutritition and the Welfare of Farms Animals. University of Queensland, Gatton, Australia: Springer International Publishing Switzerland.

[17] Russell, A. (2019). Study: Poultry gut health better under fewer light hours. Available on: https://www.wattagnet.com/articles/37504-agrilife-research-study-shows-poultry-guthealth-improved-under-fewer-light-hours?utm_source=KnowledgeMarketing\&utm_medium=email\&utm_content=Poultry\%20Update\&utm_campaign=19_04_23_Poultry\%20 Update_Tuesday\&eid $=16247$

[18] Ryder, R. D. (2000). Animal revolution: changing attitudes towards speciesism. Oxford: New York: Berg Publishers.

[19] United States Congress. (1966). Animal Wellfare Act of 1966. P. L. 89-544; 80 Stat. 350. [20] Veganuary. (2019). Available on: https://veganuary.com/starter-kit/the-free-range-myth/ 